Publ. in: Logic, Language and Meaning, 17th Amsterdam Colloquium, Amsterdam, The Netherlands, December 16-18, 2009, Revised Selected Paper: M. Aloni, H. Bastiaanse, T. de Jager and K. Schulz (eds.), Springer. Pp. 21-31, and also Publ in: Lecture Notes in Computer Science, 6042 (2010) DOI: 10.1007

\title{
Concealed Questions with Quantifiers
}

\author{
Maribel Romero* \\ University of Konstanz \\ maribel.romero@uni-konstanz.de \\ http://ling. uni-konstanz.de/pages/home/romero/index.html
}

\begin{abstract}
Concealed question noun phrases headed by the definite article have been analysed as contributing the intension of the noun phrase -an individual concept- as semantic argument of the verb. Concealed questions with quantifiers challenge this analysis. Several empirical observations will be presented and an analysis will be sketched that treats this quantification as external to the concealed question itself, making it parallel to quantificational adverbs with interrogative clauses and plural individuals. This way, the basic individual concept analysis is maintained.
\end{abstract}

Key words: Concealed question, quantifiers, quantificational variability effect, quantificational adverb, question, interrogative clause, plurality

\section{Introduction}

Concealed Question (CQ) noun phrases -italicized in (1)-(2)- combine with a question-taking verb to yield roughly the same meaning as an interrogative:

(1) Mary knows ( guessed / revealed / forgot) the capital of Italy.

(2) The waiter (knows / remembers / forgot) the dishes you ordered.

Simple CQs headed by the definite article have been analysed as contributing the regular intension of the NP -an individual concept, e.g. (4a)-(5a)- as the argument of the verb ([14], [1]). The verb is defined crosscategorially to combine both with questions and with individual concepts: (3). This analysis correctly generates the truth-conditions in $(4 \mathrm{~b})-(5 \mathrm{~b})$ for the sentences above: ${ }^{1}$

(3) a. $\llbracket k n o w_{q u} \rrbracket\left(q_{<s,<s t, t>>}\right)(z)(w)=1$ iff $\forall w^{\prime} \in \operatorname{Dox}_{z}(w)\left[q\left(w^{\prime}\right)=q(w)\right]$

b. $\llbracket k n o w_{C Q} \rrbracket\left(x_{<s, e>}\right)(z)(w)=1 \quad$ iff $\forall w^{\prime} \in \operatorname{Dox}_{z}(w)\left[x\left(w^{\prime}\right)=x(w)\right]$

(4) a. $\lambda w^{\prime \prime} . \iota x_{e}\left[\right.$ capital-of $\left(x\right.$, italy, $\left.\left.w^{\prime \prime}\right)\right]$

b. $\lambda w . \forall w^{\prime} \in \operatorname{Dox}_{m}(w)\left[\iota x_{e}\left[\operatorname{capital-of}\left(x, \mathrm{i}, w^{\prime}\right)\right]=\iota x_{e}[\operatorname{capital-of}(x, \mathrm{i}, w)]\right]$

* I would like to thank the audiences of the workshop "Frequently Asked Concealed Questions" (U. Göttingen, June 5-7, 2009), Semantik und Pragmatik im Südwesten I, the 17th Amsterdam Colloquium, and the departments of Linguistics at the universities of Geneva and Düsseldorf. Special thanks to Irene Heim, Hans Kamp, Sebastian Löbner and Ur Schlonsky for their insightful comments.

${ }^{1}$ CQs questions of higher type and the A/B ambiguity are left out of this paper. 
(5) $\quad$ a. $\quad \lambda w^{\prime \prime} . \sigma x_{e}\left[{ }^{*} \operatorname{dish}\left(x, w^{\prime \prime}\right) \wedge \operatorname{order}\left(\right.\right.$ you, $\left.\left.x, w^{\prime \prime}\right)\right]$

b. $\lambda w . \forall w^{\prime} \in D o x_{\text {waiter }}(w)\left[\sigma x_{e}\left[^{*} \operatorname{dish}\left(x, w^{\prime}\right) \wedge \operatorname{order}\left(\right.\right.\right.$ you, $\left.\left.x, w^{\prime}\right)\right]=$ $\left.\sigma x_{e}\left[^{*} \operatorname{dish}(x, w) \wedge \operatorname{order}(\mathrm{you}, x, w)\right]\right]$

The individual concept-based analysis runs into trouble when the $\mathrm{CQ}$ is headed by a quantificational determiner, as in (6). As the intension of the quantificational noun phrase is not an individual concept $(<\mathrm{s}, \mathrm{e}>)$ but a generalized quantifier $(<<\mathrm{e}, \mathrm{st}>,<\mathrm{s}, \mathrm{t}\rangle>)$, something needs to be said. A first possibility is to make the argument slot of the embedding verb of property type or higher ([4]). However, this would derive the wrong reading (see observation 1 below). A second approach uses conceptual covers and salient properties ([15], [13]). Yet a third line exploits syntactic conversion and intensionalization of traces ([7] building on [5]). For space reasons, we will not review these approaches here.

(6) The waiter remembered some / most dishes you ordered.

The goal of this paper is to sketch a solution to quantificational CQs within the individual concept line that maintains the analysis of (1)-(2) above. The idea is this: in the same way that adverbials like to some extent and for the most part can quantify over subquestions of a question, the determiners some and most can quantify over sub-individual concepts of a CQ individual concept. That is, the meaning of (6) will be roughly (though not exactly) that of (7):

(7) The waiter to some extent / for the most part remembered what dishes you ordered.

The plot of this paper is as follows. $\S 2$ reviews QVE with interrogative clauses. Three empirical observations about quantificational CQs are presented in $\S 3$, followed by a first step towards an analysis in $\S 4$. A fourth observation and a second, promisory step conclude the paper in $\S 5$.

\section{Review of Quantificational Variability Effect (QVE)}

Consider (8). Under a first approach ([3]), (8) involves quantification over individuals and the embedding verb takes a proposition, as in (9a). A second approach ([8]) maintains that the quantification is over propositions (true answers to the question) and that the embedding verb takes a proposition, as in (9b). However, [2] observe that some verbs that only embed questions, e.g. depend in (10), also allow for QVE. [2] propose that quantification is over subquestions -defined in (11)- and that the embedding verb takes a subquestion, as in (9c).

(8) John knows for the most part who cheated on the final exam.

(9) a. Most $x[x$ cheated on the final exam] [John knows that $x$ cheated on the final exam]

b. Most $p$ [ $p$ is an answer to 'who cheated on the final exam' and $p$ is true] [John knows $p$ ] 
c. Most $Q^{\prime}\left[Q^{\prime}\right.$ is a relevant subquestion of 'who cheated on the final exam'] [John knows $Q^{\prime}$ ]

(10) a. Who will be admitted depends for the most part (exclusively) on this committee.

b. *That John will be admitted depends on this committee.

(11) $Q^{\prime}$ is a subquestion of $Q$ iff it is possible that the answer to $Q^{\prime}$ provides a partial answer to $Q$.

That is, iff $\exists w^{\prime} \exists p\left[\right.$ Ans-strg $\left(Q^{\prime}\right)\left(w^{\prime}\right) \rightarrow p \wedge p$ is a partial answer to $\left.Q\right]$

\section{Three Observations about Quantificational CQs}

Observation 1. The quantification introduced by the quantifier of a CQ is not

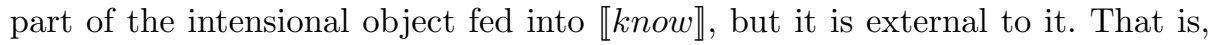
as suggested above, the (roughly) correct paraphrase of (12) is not (a) but (b). Proof of it is that, in scenario (13), the sentence underlined in (14) is false.

(12) Spy C knows most of the code.

a. $\neq$ "C knows what series of digits has the property of being most of the code."

b. = "C for the most part knows what series of digits the code has."

(13) Scenario: The code is 60 digits long. Spy $\mathrm{C}$ got the first 57 digits, but she does not know what proportion of the code her finding amounts to.

(14) Look! This is what spy $\mathrm{C}$ knows of the code. If she knew that she is so close to having the complete code, she'd be unstoppable. Luckily, she doesn't know most of the code, so she may get discouraged and give up.

Observation 2. In some languages, CQs occur quite productively with knowtype embedding verbs (know, remember, reveal, tell, etc.), with depend- type embedding verbs, and with ask-type embedding verbs. (15)-(16) illustrate this for Spanish. (See [11] and [12] for English.)

(15) "Señor Conde Lucanor" - dijo Patronio--, "(...) me gustaría contaros lo que sucedió a un rey moro con tres pícaros granujas que llegaron a palacio". Y el conde le preguntó lo que había pasado.

"Count Lucanor" - said Patronio-, "(...) I would like to tell you what (lit. the that) happened to an Arab king with three naughty urchins that arrived in the palace". And the count asked him what (lit. the that) had happened.'

http://www.ciudadseva.com/textos/cuentos/esp/juanma/lucanor/32.htm

(16) Lo que haga Marga esta semana depende de ti.

The that does-Subjunct $M$ this week depends on you

'The things Marga goes this week depend on you.'

Interestingly, in those languages, CQs admit quantificational determiners (cexamples below) and adverbs of quantification (b-examples) with know-type em- 
bedding verbs and with depend-type embedding verbs, but they are very awkward with ask-type embedding verbs. This parallels the facts about QVE with interrogatives (a-examples). The pattern is summarized in Table 1.

(17) With know:

a. Juan sabe en su mayor parte qué estudiantes copiaron en el examen. 'Juan knows for the most part which students cheated on teh exam.'

b. J. sabe en su mayor parte los estudiantes que copiaron en el examen. 'J. knows for the most part the students who cheated on the exam.'

c. Juan sabe la mayoría de los estudiantes que copiaron en el examen. 'Juan knows most students who cheated on the exam.'

(18) With depend:

a. En su mayor parte, qué haga Marga esta semana depende (exclusivamente) de ti.

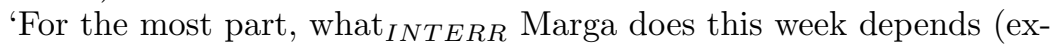
clusively) on you.

b. En su mayor parte, lo que haga Marga esta semana depende (exclusivamente) de ti.

'For the most part, the things (lit. the that) Marga does this week depend (exclusively) on you.'

c. La mayor parte de lo que haga Marga esta semana depende de ti.

'Most of what Marga will do this week depends on you.'

(19) With ask:

a.\#En su mayor parte, me preguntó qué había comido.

'For the most part, s/he asked me what ${ }_{I N T E R R} \mathrm{I} / \mathrm{she} /$ he had eaten.'

b.\#En su mayor parte, me preguntó lo que había comido.

'For the most part, s/he asked me the things (lit. the that) I/she/he had eaten.'

c. *Me preguntó la mayor parte de lo que había comido.

'S/he asked me most of what I/she/he had eaten.'

\begin{tabular}{|l|c|c|c|}
\hline & know & depend & ask \\
\hline ADV + INTERROGATIVE & $\checkmark$ & $\checkmark$ & $*$ \\
\hline ADV + CQ & $\checkmark$ & $\checkmark$ & $*$ \\
\hline DET + CQ & $\checkmark$ & $\checkmark$ & $*$ \\
\hline
\end{tabular}

Table 1. The three types of quantification and embedding verbs.

Observation 3. CQs with adverbs of quantification have more freedom in choosing the relevant set of sub-questions (or of sub-individual concepts ) than CQs headed by quantificational determiners. A first way to divide a question like (20a) into subquestions is by using the domain of the wh-phrase as the sorting key and building the relevant whether-subquestions about its members. Under this division of the question, the sub-questions quantified over in (21) are the 
ones in the set (22). This reading is also available for the combination of an adverb and a CQ, as in (20b), and for a quantificational CQ, as in (20c). ${ }^{2}$

(20) a. For the most part, John knows which students cheated.

b. For the most part, John knows the students who cheated on the exam.

c. John knows most students who cheated on the exam.

(21) Most $Q^{\prime}\left[Q^{\prime}\right.$ is a relevant subquestion of 'which students cheated'] [John knows $Q^{\prime}$ ]

(22) Set of whether-subquestions:

\{Did student 1 cheat?, Did student 2 cheat?, Did student 3 cheat?, ...

A second way to divide a question is by using a distributive plural NP - e.g. these children in (23a) - as the sorting key and forming the corresponding subquestions about its atoms. Under this division, the logical representation of (23a) in (24) quantifies over the sub-questions in (25). This reading is also available for $(23 \mathrm{~b})$, with an adverb and a CQ. In contrast, this reading is not possible if the CQ is directly headed by a quantificational determiner: sentence (23c), if acceptable, does not involve quantification over children.

(23) a. For the most part, how well these children do depends (exclusively) on their families.

b. En su mayor parte, el rendimiento diario de estos niños depende exclusivamente del ambiente familar.

'For the most part, the daily performance of these children depends exclusively on the family athmosphere.'

c. (\#) La mayor parte del rendimiento diario de estos niños depende exclusivamente del ambiente familiar.

(\#) 'Most of the daily performance of these children depends exclusively on the family athmosphere.'

(24) Most $Q^{\prime}\left[Q^{\prime}\right.$ is a relevant subquestion of 'how well these children do'] [ $Q^{\prime}$ depends (exclusively) on the family athmosphere ]

(25) Set of subquestions induced by a distributive plural NP: \{How well does child 1 do?, How well does child 2 do?, How well does child 3 do?, .. \}

Similarly to the case of distributive plurals, a third strategy uses a plural NP with a cumulative reading as the sorting key, e.g. these professors in (26a). In this case, the quantification in (27) ranges over the sub-questions in (28). This reading is also available for the adverb plus CQ variant (26b), but it is unavailable for the CQ with a quantificational determiner in (26c).

(26) a. Louise knows for the most part which books these professors recommended.

\footnotetext{
${ }^{2}$ It remains to be determined whether all the variants in (20) allow for weakly and strongly exhaustive readings.
} 
b. For the most part, Louise knows the books that these professors recommended.

c. Louise knows most books that these professors recommended.

(27) Most $Q^{\prime}\left[Q^{\prime}\right.$ is a relevant subquestion of 'which books these professors recommended'] [ Louise knows $Q^{\prime}$ ]

(28) Set of subquestions induced by a cumulative plural NP:

\{Which books did professor 1 recommend?, Which books did professor 2 recommend?, Which books did professor 3 recommend?, ...

In sum, adverbial quantification with interrogative clauses and with CQs is quite permissible as to how the original question or individual concept (IC) can be divided into smaller parts. In contrast, when the quantificational element is the determiner heading the CQ, only the head noun can be used as the sorting key, yielding a set of "whether" sub-ICs. This is summarized in Table 2.

\begin{tabular}{|l|c|c|c|}
\hline & $\begin{array}{c}\text { "whether" } \\
\text { sub-questions/ICs }\end{array}$ & $\begin{array}{c}\text { sub-questions/ICs } \\
\text { based on distr. NP }\end{array}$ & $\begin{array}{c}\text { sub-questions/ICs } \\
\text { based on cum. NP }\end{array}$ \\
\hline ADV + INTERROG & $\checkmark$ & $\checkmark$ & $\checkmark$ \\
\hline ADV + CQ & $\checkmark$ & $\checkmark$ & $\checkmark$ \\
\hline DET + CQ & $\checkmark$ & $*$ & $*$ \\
\hline
\end{tabular}

Table 2. The three types of quantification and possible divisions.

\section{First Step towards an Analysis}

[2] propose the definitions (11) and (roughly) (29) to handle adverbial quantification with interrogative clauses. As the reader can check for herself, the definitions allow for the three types of divisions illustrated in the previous section.

(29) A set $\operatorname{Part}(Q)(w)$ of questions $Q^{\prime}$ is a division of $Q$ into subquestions in $w$ iff these subquestions taken together exhaust the original question. More formally: iff

i. For each $Q^{\prime} \in \operatorname{Part}(Q)(w), Q^{\prime}$ is a subquestion of $Q$; and

ii $\quad$ Either a. $\cap\left\{\operatorname{Ans-wk}\left(Q^{\prime}\right)(w): Q^{\prime} \in \operatorname{Part}(Q)(w)\right\}=\operatorname{Ans-wk}(Q)(w)$

or $\quad$ b. $\cap\left\{\operatorname{Ans}-\operatorname{strg}\left(Q^{\prime}\right)(w): Q^{\prime} \in \operatorname{Part}(Q)(w)\right\}=\operatorname{Ans}-\operatorname{strg}(Q)(w)$

Now we need something similar for adverbial quantification with CQs. The idea is to take the original IC expressed by the CQ noun phrase and divide it into natural sub-individual concepts that, taken together, exhaust the original IC. The proposed definition is the following: ${ }^{3}$

(30) A set $\operatorname{Part}\left(x_{<s, e>}\right)$ of natural individual concepts $y_{<s, e>}$ is a division of $x_{<s, e>}$ into sub-individual concepts iff:

For all $w \in \operatorname{Dom}(x): \sqcup\{y(w): y \in \operatorname{Part}(x)\}=x(w)$.

\footnotetext{
${ }^{3}$ The restriction to natural ICs in (30) aims to eliminate the empty $<$ s,e $>$ function from the division set and to prevent spurious splitting of e.g. the IC $\left[<w_{100}, 2>\right.$, $<w_{101}, 2>$ in $(33)$ into two separate unnatural ICs $\left[<w_{100}, 2>\right]$ and $\left[<w_{101}, 2>\right]$.
} 
Let us apply this definition to CQs with adverbial quantification. Consider first example (31a) and its truth conditions (31b). The (partial) IC function expressed by the NP is formulated and illustrated in (32) (assuming for simplicity that there are only three students under consideration: student 1 , student 2 and student 3). How can we divide this original IC into a set of sub-ICs? One possible avenue allowed by the definition above is to divide it by individual students, that is, to carve out sub-ICs like "the student 1 who cheated on the exam". This produces the set (33), which derives the intended reading of the sentence.

(31) a. For the most part, John knows the students who cheated on the exam. $(=(20 \mathrm{~b}))$

b. $\lambda w$. Most $y_{<s, e>}$

$\left[y_{<s, e>} \in \operatorname{Part}(\llbracket\right.$ the students that cheated on exam $\left.\rrbracket)\right]$

[John knows $y_{<s, e>}$ in $w$ ]

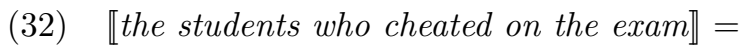

$\lambda w^{\prime} . \sigma z_{e}\left[{ }^{*} \operatorname{student}\left(z, w^{\prime}\right) \wedge \operatorname{cheated}\left(z, w^{\prime}\right)\right]$

E.g.: $\left[\begin{array}{lcc}w_{100} & \rightarrow & 1+2+3 \\ w_{101} & \rightarrow & 2 \\ w_{102} & \rightarrow & \#\end{array}\right]$

(33) $\left\{\lambda w \cdot \iota z_{e}[\operatorname{student}(z, w) \wedge z=\operatorname{stud} 1 \wedge \operatorname{cheated}(z, w)]\right.$,

$\lambda w . \iota z_{e}[\operatorname{student}(z, w) \wedge z=\operatorname{stud} 2 \wedge \operatorname{cheated}(z, w)]$

$\left.\lambda w \cdot \iota z_{e}[\operatorname{student}(z, w) \wedge z=\operatorname{stud} 3 \wedge \operatorname{cheated}(z, w)]\right\}$

E.g.: $\left\{\left[\begin{array}{l}w_{100} \rightarrow 1 \\ w_{101} \rightarrow \# \\ w_{102} \rightarrow \#\end{array}\right],\left[\begin{array}{l}w_{100} \rightarrow 2 \\ w_{101} \rightarrow 2 \\ w_{102} \rightarrow \#\end{array}\right],\left[\begin{array}{l}w_{100} \rightarrow 3 \\ w_{101} \rightarrow \# \\ w_{102} \rightarrow \#\end{array}\right]\right\}$

Consider now example (34a) and its logical representation in (34b). The intension of the NP is spelled out and exemplified in (35). Recall that, under the intended reading, the division of the original individual concept uses as sorting key the cumulative NP these professors. This means that we have to carve out "book" sub-ICs based on the professors, e.g. the sub-IC "the books that professor 1 recommended". This yields the division set (36), which meets definition (30):

(34) a. For the most part, Louise knows the books that these professors recommended. $\quad(=(26 \mathrm{~b}))$

b. $\lambda w$. Most $y_{<s, e>}$

$\left[y_{<s, e>} \in \operatorname{Part}(\llbracket\right.$ the books that these profs recommended $\left.\rrbracket)\right]$

[Louise knows $y_{<s, e>}$ in $w$ ]

(35) 【the books that these professors recommended $\rrbracket=$

$\lambda w^{\prime} . \sigma z_{e}\left[{ }^{*} \operatorname{book}\left(z, w^{\prime}\right) \wedge{ }^{* *}\right.$ recommend(these.profs, $\left.\left.z, w^{\prime}\right)\right]$

E.g.: $\left[\begin{array}{lcc}w_{100} & \rightarrow \mathrm{a}+\mathrm{b}+\mathrm{c}+\mathrm{d}+\mathrm{e} \\ w_{101} & \rightarrow & \mathrm{e}+\mathrm{f}+\mathrm{g} \\ w_{102} & \rightarrow & \#\end{array}\right]$

(36) $\left\{\lambda w \cdot \sigma z_{e}\left[{ }^{*} \operatorname{book}(z, w) \wedge \operatorname{recommend}(\operatorname{prof} 1, z, w)\right]\right.$, $\lambda w \cdot \sigma z_{e}\left[{ }^{*} \operatorname{book}(z, w) \wedge \operatorname{recommend}(\operatorname{prof} 2, z, w)\right]$, 


$$
\begin{aligned}
& \left.\lambda w \cdot \sigma z_{e}\left[{ }^{*} \operatorname{book}(z, w) \wedge \operatorname{recommend}(\operatorname{prof} 3, z, w)\right]\right\}
\end{aligned}
$$

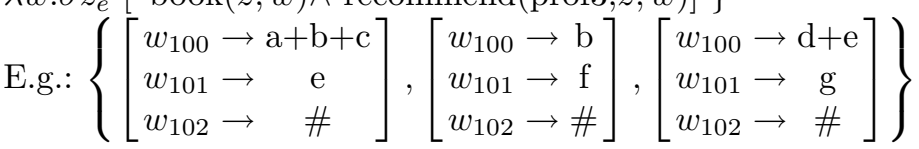

Let us turn to CQs with quantificational determiners. Now only divisions into "whether" sub-ICs should be allowed. This can be achieved by defining a lexical entry for the determiner that builds the original IC out of the N'-property and requires it to be divided into (possibly partial) constant functions, as follows:

$$
\begin{aligned}
& \lambda P_{<e, s t>} \cdot \lambda Q_{<s e, s t>} \cdot \lambda w . \\
& \quad \operatorname{MOST} y_{<s, e>}\left[y_{<s, e>} \in C \operatorname{Part}\left(\lambda w^{\prime} . \sigma z_{e}\left[P(z)\left(w^{\prime}\right)\right]\right)\right]\left[Q\left(y_{<s, e>}\right)(w)\right]
\end{aligned}
$$

(38) A set $C \operatorname{Part}\left(x_{<s, e>}\right)$ of natural individual concepts $y_{<s, e>}$ is a constantbased division of $x_{<s, e>}$ into sub-individual concepts iff:

i. For all $y_{<s, e>} \in C$ Part: $y_{<s, e>}$ is a constant function, and

ii. For all $w \in \operatorname{Dom}(x): \sqcup\{y(w): y \in \operatorname{Part}(x)\}=x(w)$.

For (39), we will obtain (32) as the original IC and will be able to use the set (33) as the constant-based division of it, hence deriving the desired reading. For (40), the IC in (35) will be built, but we will not be able to use the set (36), as this set contains non-constant functions. Hence, the intended reading is unavailable. ${ }^{4}$

(39) a. John knows most students who cheated on the exam. $(=(20 \mathrm{c}))$

b. $\lambda w$. MOST $y_{<s, e>}$

$\left[y_{<s, e>} \in C \operatorname{Part}\left(\lambda w^{\prime} . \sigma z_{e}\left[\llbracket\right.\right.\right.$ students that cheated on exam $\left.\left.\left.\rrbracket(z)\left(w^{\prime}\right)\right]\right)\right]$ [John knows $y_{<s, e>}$ in $w$ ]

(40) a. Louise knows most books that these professors recommended. $(=(26 \mathrm{c}))$

b. $\lambda w$. MOST $y_{<s, e>}$

$\left[y_{<s, e>} \in C \operatorname{Part}\left(\lambda w^{\prime} . \sigma z_{e}\left[\llbracket b o o k s\right.\right.\right.$ that these profs recomm. $\left.\left.\left.\rrbracket(z)\left(w^{\prime}\right)\right]\right)\right]$

[Louise knows $y_{<s, e>}$ in $w$ ]

To sum up, the quantification induced by a determiner in a CQ is similar to adverbial quantification with interrogative clauses and CQs in that it is external to the content of the question/IC (observation 1) and in that it is compatible only with certain embedding verbs (observation 2). However, a determiner in a $\mathrm{CQ}$ allows only for a division of the original indivual concept into constant subconcepts, whereas abverbial quantification allows for divisions into non-constant functions. The question remains, why should adnominal and adverbial quantification differ this way. This is briefly addressed in $\S 5$.

\footnotetext{
${ }^{4}$ In this paper, only name-like answers like (iA) are considered and intensional answers like (iA') are left aside. The latter would require a more permissible type of division than (38) (H. Kamp, p.c.). I leave this issue for future research.

(i) Q: Which students cheated on the final exam?

A: Bill Smith and Paul Taylor.

A': The dummest student in the class and the busiest student in the class.
} 


\section{A Fourth Observation and a Second, Promisory Step}

It is well-known that adverbials producing QVE over individuals (type e) can "target" different NPs in the clause $([9],[10])$. We note that they can also target NPs in an embedded clause, e.g. the NPs underlined in (41). In other words, the difference between $\mathrm{Adv}+\mathrm{CQ}$ and Det $+\mathrm{CQ}$ in $\S 4$ is just an instance of a more general contrast between Adv+Plural, as in (41), and Det+Plural, as in (42).

(41) a. For the most part, John read the books that these professors recommended.

b. For the most part, John can achieve the performance that those brilliant students achieved on the test.

(42) a. John read most (of the) books that these professors recommended.

b. (\#) John can achieve most of the performance that those brilliant students achieved on the test.

[10] analyse two constructions with most involving plural individuals. Determiner most directly quantifies over the set of individuals denoted by its sister $\mathrm{NP}$, as (43). In contrast, for the most part directly quantifies over a set of events, as in (44); only indirectly is QVE over individuals derived, through a contextual mapping from events to individuals (see [10] for justification and details).

(43) Truth conditions for 'Most of NP VP':

$\exists x^{\prime}\left[x^{\prime} \leq \llbracket \mathrm{NP} \rrbracket \wedge\left|x^{\prime}\right|>1 / 2|\llbracket \mathrm{NP} \rrbracket| \wedge \forall x^{\prime \prime}\left[x^{\prime \prime} \leq x^{\prime} \rightarrow \llbracket \mathrm{VP} \rrbracket\left(x^{\prime \prime}\right)\right]\right]$

Consider the plural individual $\llbracket \mathrm{NP} \rrbracket$, e.g. $x$. There is an $x^{\prime}$ that is a major part of $x$ such that, for all subindividuals $x^{\prime \prime}$ of $x^{\prime}, \llbracket \mathrm{VP} \rrbracket\left(x^{\prime \prime}\right)$ holds.

(44) Truth conditions of 'For the most part NP VP':

$\exists e\left[p(e) \wedge \exists e^{\prime}\left[e^{\prime} \leq e \wedge\left|e^{\prime}\right|>1 / 2|e| \wedge \forall e^{\prime \prime}\left[e^{\prime \prime} \leq e^{\prime} \rightarrow q\left(e^{\prime \prime}\right)\right]\right]\right]$

There is a plural event $e$ for which $p(e)$ holds and there an event $e^{\prime}$ that is a major part of $e$ such that, for all subevents $e^{\prime \prime}$ of $e^{\prime}, q\left(e^{\prime \prime}\right)$ holds.

( $p=$ non-focused material; $q=$ focused material)

This idea applies to our examples as follows. In the case of plural individuals, determiner quantification yields the truth conditions in (45), where the relevant set of books is univocally quantified over. Adverbial quantification generates the truth conditions in (46), where we quantify over subevents of $e$. If those subevents are "carved out" in a one-to-one mapping with the individual books, we get the same reading as in (45); if they are "carved out" in a one-to-one mapping with the professors, we get a QVE reading over professors.

(45) John read most of the books that these professors recommended.

$\lambda w . \exists x^{\prime}\left[x^{\prime} \leq \llbracket\right.$ the books that these profs recommended $\rrbracket(w) \wedge$

$\left|x^{\prime}\right|>1 / 2 \mid \llbracket$ the books that these profs recommended $\rrbracket(w) \mid \wedge$

$\forall x^{\prime \prime}\left[x^{\prime \prime} \leq x^{\prime} \rightarrow\right.$ John read $x^{\prime \prime}$ in $\left.\left.w\right]\right]$

(46) For the most part, John $\operatorname{read}_{F}$ the books that these profs. recommended. $\lambda w . \exists e[\operatorname{Agent}(e$, john $) \wedge$ Theme $(e, \llbracket$ the books these profs rec. $\rrbracket(w)) \wedge e$ is in $\left.w \wedge \exists e^{\prime}\left[e^{\prime} \leq e \wedge\left|e^{\prime}\right|>1 / 2|e| \wedge \forall e^{\prime \prime}\left[e^{\prime \prime} \leq e^{\prime} \rightarrow \operatorname{read}\left(e^{\prime \prime}\right)\right]\right]\right]$ 
I tentatively propose that quantification with CQs is done in a parallel way. Determiner quantification leads to truth conditions like (48). The original IC is converted into the corresponding plural sum of constant sub-ICs according to the definition of PL-DIV in (47), and most univocally quantifies over those sub-ICs. In contrast, adverbial quantification leads to truth conditions like (49). If the subevents quantified over are in a one-to-one mapping with ICs of the shape "the book X that (some of) these professors recommended", we obtained the same reading as in (48); if the subevents are in one-to-one mapping with ICs like "the books that professor X recommended", we derive the intended reading.

(47) A sum of individual concepts $y_{1,<s, e>}+y_{2,<s, e>}+\ldots+y_{n,<s, e>}$ is a plural division of an individual concept $x_{<s, e>}$, PL-DIV $(x)$, iff:

i. For all atomic $y \leq y_{1}+y_{2}+\ldots+y_{n}, y$ is a (possibly partial) constant function, and

ii. For all $w \in \operatorname{Dom}(x): y_{1}+y_{2}+\ldots+y_{n}=x(w)$.

(48) John knows most (of the) books that these professors recommended. $\lambda w . \exists x^{\prime}\left[x^{\prime} \leq \mathrm{PL}-\mathrm{DIV}(\llbracket\right.$ the books that these profs recommended $\rrbracket) \wedge$ $\left|x^{\prime}\right|>1 / 2 \mid \mathrm{PL}-\mathrm{DIV}(\llbracket$ the books that these profs recommended $\rrbracket) \mid \wedge$ $\forall x^{\prime \prime}\left[x^{\prime \prime} \leq x^{\prime} \rightarrow\right.$ John knows $x^{\prime \prime}$ in $\left.w\right]$ ]

(49) For the most part, John knows $F$ the books these profs. recommended. $\lambda w . \exists e[\operatorname{Agent}(e$, john $) \wedge$ Theme $(e, \llbracket$ the books these profs rec. $\rrbracket) \wedge e$ is in $\left.w \wedge \exists e^{\prime}\left[e^{\prime} \leq e \wedge\left|e^{\prime}\right|>1 / 2|e| \wedge \forall e^{\prime \prime}\left[e^{\prime \prime} \leq e^{\prime} \rightarrow \operatorname{know}\left(e^{\prime \prime}\right)\right]\right]\right]$

\section{References}

1. Aloni, M.: Concealed questions under cover. Grazer Ph. St. 77, pp. 191-216 (2008)

2. Beck, S., Sharvit, Y.: Pluralities of questions. J. Sem. 19, pp. 105-157 (2002)

3. Berman, S.: On the semantics and LF of Wh-clauses, UMass Ph.D. diss. (1991)

4. Frana, I.: The de re analysis of concealed questions. In: Proc. SALT XVI (2006)

5. Frana, I.: Concealed questions: in search of answers. UMass Ph.D. diss. (2009)

6. Heim, I.: Concealed Questions. In: Bäuerle, R., Egli, U., von Stechow, A. (eds.) Semantics from different points of view, pp. 51-60. Springer, Berlin (1979)

7. Heim, I.: Nouns as predicates of individual concepts?. Talk at the Workshop Frequently Asked Concealed Questions, U. Götingen (2009)

8. Lahiri, U.: Questions and answers in embedded contexts. Oxford U. Press (2002)

9. Löbner, S.: Polarity in natural language: predication, quantification and negation in particular and characterizing sentences. L\&P 23, 213-308 (2000)

10. Nakanishi, K., Romero, M.: Two Constructions with Most and their Semantic Properties. In: Proceedings of NELS 34, pp. 453-467. GLSA, Amherst (2004)

11. Nathan, L.: On the interpretation of concealed questions. MIT Ph. D. diss. (2006)

12. Percus, O.: Concealed questions as concealed questions. Talk at the Workshop Frequently Asked Concealed Questions, U. Götingen (2009)

13. Roelofsen, F., Aloni, M.: Perspectives on concealed questions. In: Proceedings of SALT XVIII. (2008) (Revised version Nov. 2009)

14. Romero, M.: Concealed questions and specificational subjects. L\&P 28, 687-737 (2005)

15. Schwager, M.: Keeping prices low: an answer to a concealed question. Proceedings of Sinn und Bedeutung XII. (2007) 